\title{
A de novo 11p13 Microduplication in a Patient with Some Features Invoking Silver-Russell Syndrome
}

\author{
O. Palumbo $^{a}$ T. Mattina ${ }^{b}$ P.Palumbo ${ }^{a, c}$ M. Carella ${ }^{a}$ C.S. Perrotta ${ }^{d}$ \\ ${ }^{a}$ Medical Genetics Unit, IRCCS Casa Sollievo della Sofferenza, San Giovanni Rotondo, b Department of Pediatrics, \\ Medical Genetics University of Catania, Catania, 'Department of Biology, University of Bari, Bari, and \\ ${ }^{\mathrm{d}}$ Medical Genetics Unit, P.O. Vittorio Emanuele III, Gela, Italy
}

\section{Key Words}

11 p13 microduplication · Silver-Russell syndrome .

Single-nucleotide polymorphism array analysis

\begin{abstract}
Patients with Silver-Russell syndrome (SRS) show an intrauterine and postnatal growth restriction associated with a variable spectrum of additional features. Genetic or epigenetic alterations on chromosomes 7 and 11 can be detected in several SRS patients; however, a large fraction of cases remains with unknown genetic etiology. Here, we describe the clinical and molecular findings of a patient with a phenotype invoking SRS showing intrauterine and postnatal growth retardation, psychomotor retardation, relative macrocephaly, slightly triangular face with pointed chin, clinodactyly, and a slight body asymmetry, in whom single-nucleotide polymorphism oligonucleotide array analysis led to the identification of a de novo $11 \mathrm{p} 13$ duplication containing many genes that could be functionally related with the observed clinical features. Many deletions of chromosome $11 \mathrm{p} 13$, resulting in WAGR (Wilms tumor, aniridia, genital anomalies, mental retardation) syndrome, have been described, while only few duplications spanning the same region have been
\end{abstract}

\section{KARGER}

E-Mail karger@karger.com

www.karger.com/msy reported so far. To our knowledge, this is the first reported case presenting a SRS carrier of an $11 \mathrm{p} 13$ duplication. We propose candidate genes for the observed traits, and in particular, we discuss the possible role of the involvement of 2 noncoding RNAs in the etiology of the phenotype.

(c) 2013 S. Karger AG, Basel

Silver-Russell syndrome (SRS, OMIM 180860) is a clinically and genetically heterogeneous disorder characterized by intrauterine and postnatal growth restriction as well as body asymmetry associated with a variable spectrum of additional features: relative macrocephaly, triangular face with a prominent forehead, pointed chin, and 5 th finger clinodactyly. Some patients show a mild motor and cognitive delay (learning difficulties and speech delay). By molecular genetic testing, in about $50 \%$ of patients, genetic/epigenetic alterations can be detected: in $7-10 \%$ of cases, a maternal uniparental disomy of chromosome 7 [UPD(7)mat] can be found, while a methylation defect of the imprinting control region 1 in $11 \mathrm{p} 15$ is reported in more than $38 \%$ of patients. Usually, the $11 \mathrm{p} 15$ epimutation carriers show the more classical SRS phenotype, while UPD(7)mat carriers are more mildly affected. (c) 2013 S. Karger AG, Basel

$1661-8769 / 13 / 0051-0011 \$ 38.00 / 0$
Massimo Carella

Medical Genetics Unit, IRCCS Casa Sollievo della Sofferenza

Viale Cappuccini

IT-71013 San Giovanni Rotondo (Italy)

E-Mail m.carella@operapadrepio.it 
A

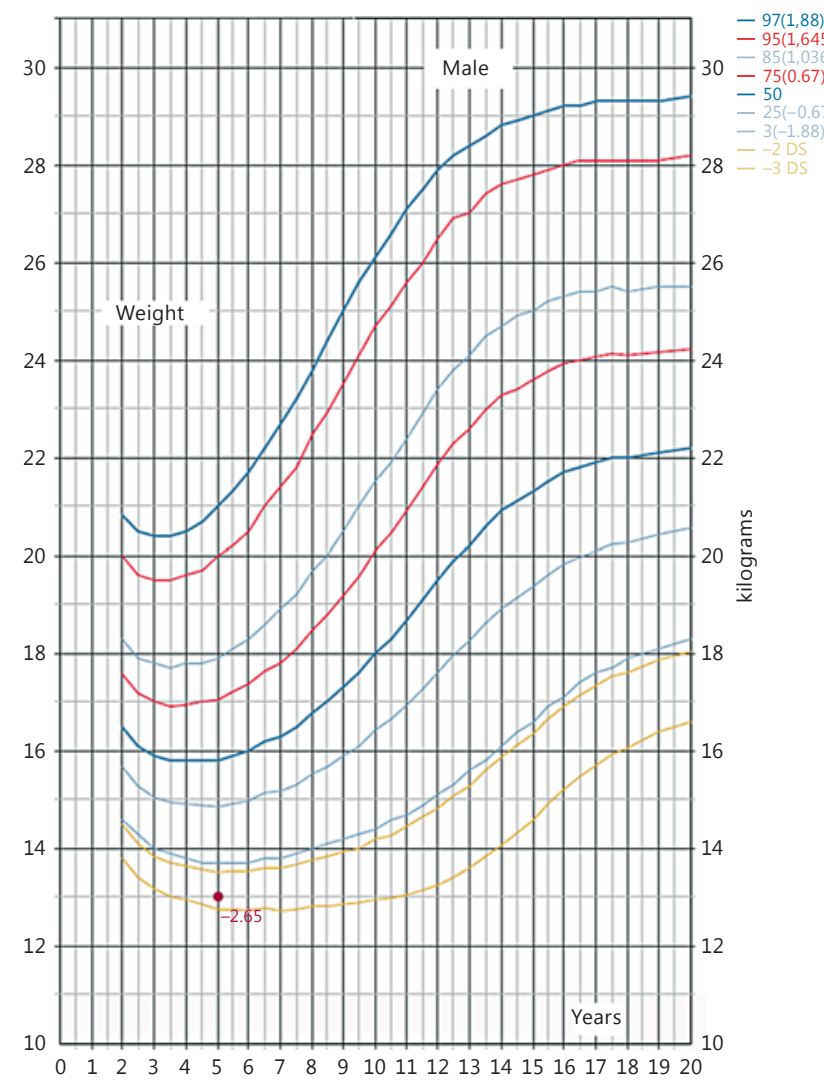

B

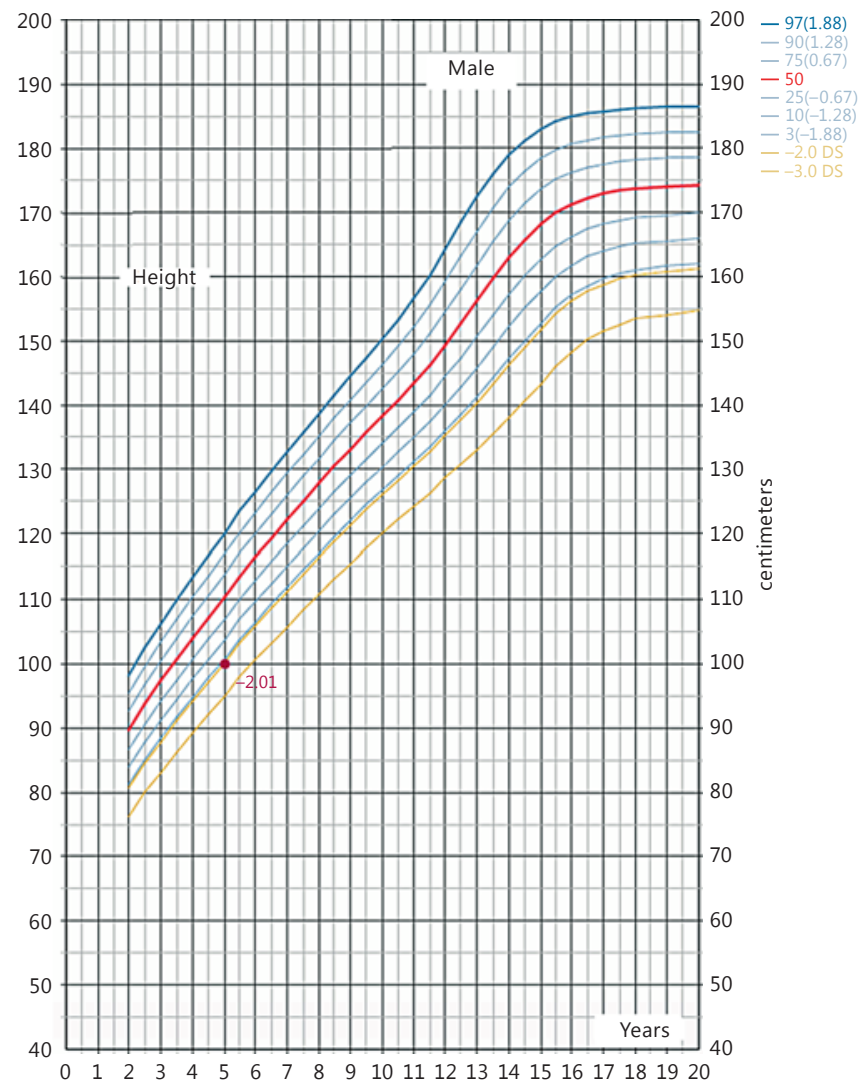

Fig. 1. Growth curves. A Weight-for-age percentile, 0-20 years. B Height-for-age percentile, 0-20 years.

Nevertheless, many exceptions have been reported, thereby making a strict genotype-phenotype correlation difficult. In addition to these 2 major disturbances, microscopically detectable structural aberrations affecting numerous chromosomes have been documented, but only the ones involving chromosomes 7,11 and 17 were consistent with strict diagnostic criteria of SRS [Abu-Amero et al., 2008; Coutton et al., 2012]. However, about $50 \%$ of the remaining SRS patients are molecularly unexplained (idiopathic) [Eggermann et al., 2010]. In this study, we report on a 5-years-old boy showing growth retardation, slight body asymmetry and many of the clinical features of SRS, in which single-nucleotide polymorphism (SNP) array analysis identified a de novo duplication of chromosome $11 \mathrm{p} 13$ encompassing $4.3 \mathrm{Mb}$ that include 42 genes. To date, only few studies have described submicroscopic chromosomal alterations in SRS or SRS-like cases, and none of them involves the region 11p13 [Bruce et al., 2010; Spengler et al., 2012]. Also, we discuss the phenotype of the patient in relationship to the gene content of the identified microduplication, and in particular, we propose CAPRIN1, SLC1A2 and FJX1 as possible candidate genes for the psychomotor delay and ELP4 for the intrauterine and postnatal growth restriction. Finally, we suggest a possible involvement of MIR1343 and LINC00294 in the 11p13-duplication phenotype observed in our patient.

\section{Clinical Report}

The male patient was born at the 41st week of gestation from nonconsanguineous healthy parents with no family history of congenital anomalies or developmental delay. During pregnancy, intrauterine growth retardation was reported. At birth, he was small for gestational age with a weight of 2,680 $\mathrm{g}$ ( $<3 \mathrm{rd}$ percentile), a
12

Mol Syndromol 2014;5:11-18 DOI: $10.1159 / 000356459$
Palumbo/Mattina/Palumbo/Carella/ Perrotta 
length of $49 \mathrm{~cm}$ (3-10th percentile) and a head circumference of 35 $\mathrm{cm}$ (50th percentile). He did not show either icterus or asphyxia. The sucking was documented as valid. He was referred at 18 months for evaluation of dysmorphic features, pre- and postnatal growth retardation, psychomotor retardation, and skeletal asymmetry. At that time, his weight was $8 \mathrm{~kg}(<<3 \mathrm{rd}$ percentile), his length $76 \mathrm{~cm}$ $(<<3$ rd percentile) and his head circumference $46.6 \mathrm{~cm}(10-25$ th percentile). He held the head at 5 months, sat independently at 8 months and walked without support at 15 months. Because of the right truncal hypotonia, he performed physiotherapy from months 9 to 15 . Recurrent respiratory infections were reported. At 4 years, he showed a delayed skeletal age of 2 years and also left cryptorchidism which was surgically corrected. An evaluation at 5 years noted a weight of $13 \mathrm{~kg}$ ( $<3 \mathrm{rd}$ percentile), a height of $100 \mathrm{~cm}(<3 \mathrm{rd}$ percentile) and a head circumference of $49,5 \mathrm{~cm}$ (25-50th percentile) (fig. 1). Physical examination showed hypotrophic and normotonic muscle masses, slight body asymmetry and mild dysmorphic features including: relative macrocephaly, slightly triangular face with high forehead and pointed chin, deep-set eyes, horizontal palpebral fissures, long eyelashes, left convergent strabismus, high and wide nose bridge, large low-set and anteverted ears, hypoplastic tragus, downturned corners of the mouth, slight retrognathia, hands and feet with a 4th and 5th finger clinodactyly, scapular winging, and valgus knees (fig. 2). At brain magnetic resonance, nonspecific white matter anomalies were noticed.

A diagnosis of SRS has been proposed based on the following criteria: intrauterine growth retardation (birth weight or length below the 3rd percentile), lack of postnatal catch-up growth (at 18 months of age, the weight and the length were both $<<3$ rd percentile) and at least 2 of the following criteria: typical face (slightly triangular face with high forehead and pointed chin, downturned corners of the mouth, and ear anomalies), relative macrocephaly, body asymmetry, and 5th finger clinodactyly. The standard Gbanding karyotype analysis and the search for epimutations in 11 p15 and UPD(7)mat were all negative.

\section{Material and Methods}

Blood was obtained from the proband and his parents after signed informed consent. Genomic DNA samples were isolated from peripheral blood lymphocytes by using BioRobot EZ1 (Quiagen, Solna, Sweden). DNA concentration and purity were determined with a ND-1000 Spectrophotometer (NanoDrop Technologies, Berlin, Germany), while for the detection of submicroscopic genomic imbalances, we typed genomic DNA by using the Genome-Wide Human SNP 6.0 Array (Affymetrix, Santa Clara, Calif., USA), including $1.8 \mathrm{M}$ oligonucleotide markers, as previously described [Palumbo et al., 2012]. Microarrays were washed and stained with the Affymetrix Fluidics Station 450 and scanned with the Affymetrix GeneChip Scanner 3000 using the Command Console software (Affymetrix). Copy number analysis was performed with the Genotyping Console software version 4.1 (Affymetrix) using annotation file version NA32 (hg19) and an in-house reference file consisting of 90 samples. Physical mapping and gene locations were obtained from the University of California Santa Cruz (UCSC, http://genome.ucsc.edu/cgi-bin/hgGateway) Genome Browser, assembly GRCh37.

11 p13 Microduplication in a SRS-Like Patient
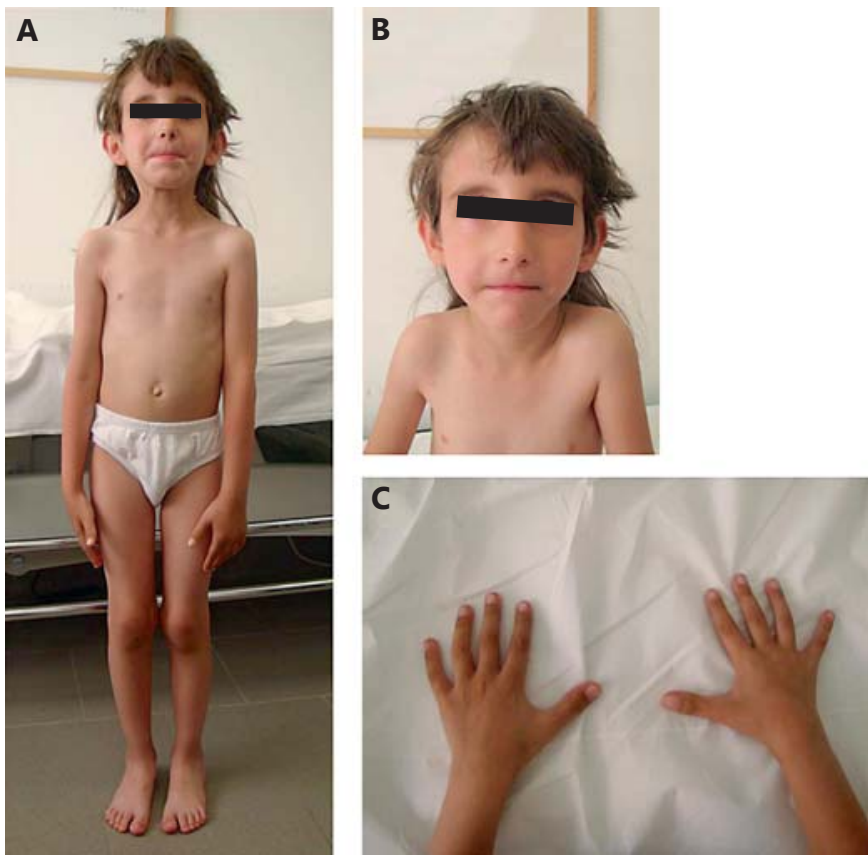

Fig. 2. A Patient at the age of 5 years. Note hypotrophic and normotonic muscle masses and body asymmetry. B Facial features. Note the relative macrocephaly, high forehead with pointed chin, deep-set eyes, horizontal palpebral fissures, long eyelashes, left convergent strabismus, high and wide nose bridge, downturned corners of the mouth, and slight retrognathia. C Hands. Note the 4 th and 5 th finger clinodactyly.

\section{Results}

The SNP array analysis revealed an approximately 4.3-Mb-sized duplication in 11p13, from CN_576312 $(31,464,790 \mathrm{bp})$ to SNP_A-2303898 (35,788,567 bp) which were the first and the last duplicated oligonucleotide starting from the telomere, respectively. The flanking normal probes were SNP_A-1958585 (31,454,975 bp, telomeric) and CN_567779 (35,790,243 bp, centromeric). The duplication was absent in the parent (fig. 3A), indicating a de novo origin of the rearrangement, and encompassed 42 genes (fig. 3B). According to the ISCN 2013 nomenclature, the rearrangement can be described as: arr[hg19] 11p13(31,454,975×2,31,464,790-35,788,567× $3,35,790,243 \times 2) \mathrm{dn}$. The $11 \mathrm{p} 13$ microduplication in the patient was then confirmed by a second experiment using the GeneChip Human Mapping 250K NspI Array (Affymetrix) (data not shown). 
A
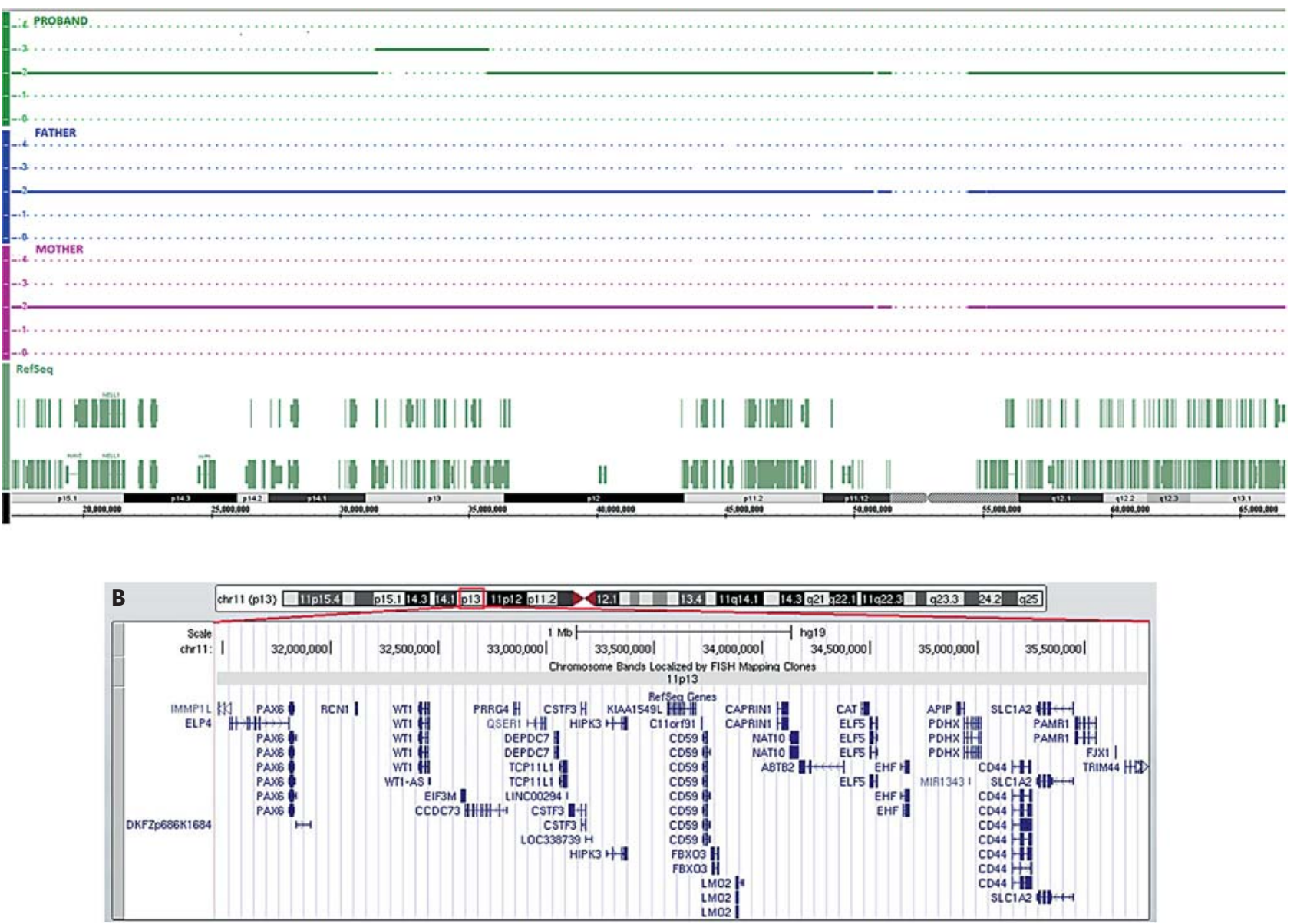

Fig. 3. A Copy number state profile of the proband (upper panel), his father (middle panel) and his mother (lower panel). Screenshot showing the duplication at 11p13 in the patient from the analysis with Affymetrix Genotyping Console software. B Gene content of the duplicated region based on UCSC Genome browser build February 2009, hg19.

\section{Discussion}

To our knowledge, this is the first reported patient with Silver-Russell syndrome features associated with a duplication of approximately $4.3 \mathrm{Mb}$, encompassing 42 genes including PAX6 and WT1, of chromosome region $11 \mathrm{p} 13$.

Up to now, chromosomal analysis of SRS or SRS-like patients has been based on conventional karyotype analysis while a systematic screen for submicroscopic alterations, using high-resolution technologies such as SNP arrays platforms, has been performed rarely. To the best of our knowledge, in none of these studies, a duplication encompassing the $11 \mathrm{p} 13$ region has been described before [Bruce et al., 2010; Spengler et al., 2012].

The duplication identified in our patient was found to be de novo, covers a region which is not reported as a copy number variant in the Database of Genomic Variants (http://projects.tcag.ca/variation/), has a high gene content, and thus is therefore likely to be a pathogenic imbalance. Moreover, we did not find previously described patients with an overlapping duplication of comparable size in publicly available databases (DECIPHER, http://decipher.sanger.ac.uk; ECARUCA, http://ecaruca.net; ISCA, http://iscaconsortium.org).
14

Mol Syndromol 2014;5:11-18 DOI: $10.1159 / 000356459$
Palumbo/Mattina/Palumbo/Carella/ Perrotta 
Table 1. Comparison of clinical features of SRS patients, $11 \mathrm{p} 13$ duplication carriers reported in the literature and our patient

\begin{tabular}{|c|c|c|c|c|c|c|c|c|c|}
\hline & Present case & $\begin{array}{l}\text { Sanchez et } \\
\text { al. [1974] }\end{array}$ & $\begin{array}{l}\text { Palutke et } \\
\text { al. [1980] }\end{array}$ & $\begin{array}{l}\text { Strobel et } \\
\text { al. [1980] }\end{array}$ & $\begin{array}{l}\text { Lavedan et } \\
\text { al. [1989] }\end{array}$ & $\begin{array}{l}\text { Speleman et } \\
\text { al. [1991] }\end{array}$ & $\begin{array}{l}\text { Aalfs et } \\
\text { al. [1997] }\end{array}$ & $\begin{array}{l}\text { Aradhya et } \\
\text { al. [2011] }\end{array}$ & $\begin{array}{l}\text { Dolan et } \\
\text { al. [2011] }\end{array}$ \\
\hline Duplicated region & $11 \mathrm{p} 13$ & $11 \mathrm{p} 12 \mathrm{p} 14$ & $11 \mathrm{p} 12 \mathrm{p} 14$ & $11 \mathrm{p} 11.3 \mathrm{p} 14.1$ & $11 \mathrm{p} 12 \mathrm{p} 14$ & $\begin{array}{l}\text { 11p13p14 or } \\
11 \mathrm{p} 14 \mathrm{p} 15\end{array}$ & $11 \mathrm{p} 12 \mathrm{p} 13$ & $11 \mathrm{p} 13$ & $11 \mathrm{p} 13 \mathrm{p} 14.1$ \\
\hline $\begin{array}{l}\text { Coordinates of the minimal } \\
\text { duplication, bp (hg19) }\end{array}$ & $\begin{array}{l}31,464,790- \\
35,788,567\end{array}$ & na & na & na & na & na & na & $\begin{array}{l}31,722,682- \\
31,857,737\end{array}$ & $\begin{array}{l}29,704,680 \\
35,198,172\end{array}$ \\
\hline $\begin{array}{l}\text { Coordinates of the maximal } \\
\text { duplication, bp (hg19) }\end{array}$ & $\begin{array}{l}31,454,975- \\
35,790,243\end{array}$ & na & na & na & na & na & na & $\begin{array}{l}31,705,077- \\
31,870,663\end{array}$ & $\begin{array}{l}29,634,121- \\
35,209,552\end{array}$ \\
\hline
\end{tabular}

Growth
$\begin{aligned} & \text { Intrauterine growth } \\ & \text { retardation }\end{aligned}$
$\begin{aligned} & \text { Postnatal growth } \\ & \text { retardation }\end{aligned}$

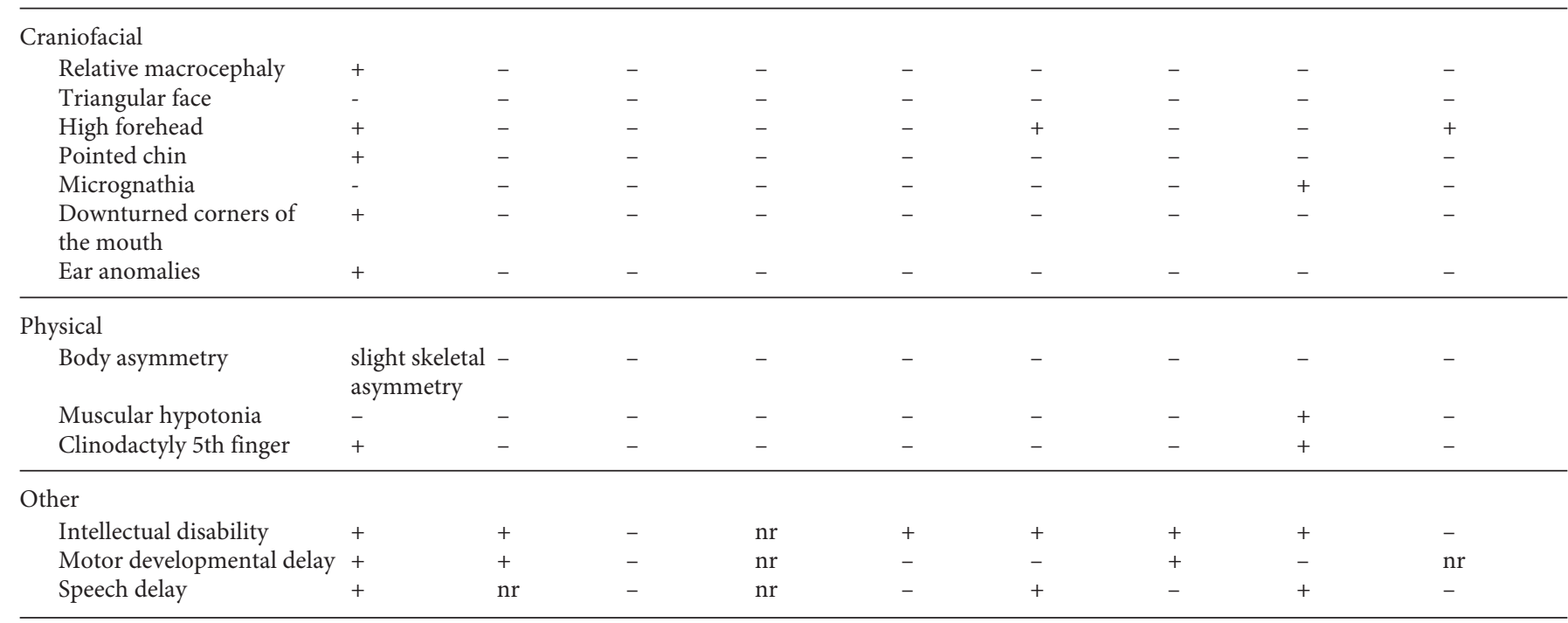

$+=$ Feature present; - = feature absent; na = not available; $\mathrm{nr}=$ feature not reported.

In the literature, deletions in $11 \mathrm{p} 13$ encompassing PAX6 and WT1 genes have long been known and associated with the WAGR syndrome that is characterized by Wilms tumor, aniridia, genital abnormalities, and mental retardation. In particular, loss-of-function mutations in PAX6 cause the aniridia phenotype while the deletion of the WT1 gene has been associated with the increased risk to develop a Wilms tumor [Fischbach et al., 2005].

The phenotype of the reciprocal $11 \mathrm{p} 13$ duplication and the dose effect of the genes included in the region are less well-known. To our knowledge, there are a total of 14 patients reported in the literature and only one, described by Aradhya et al. [2011], had a duplication smaller than the one reported in our patient. Among the 14 published cases of duplications, 6 have been excluded in the clinical comparison since their extent into the $11 \mathrm{p} 15$ imprinted region.

Of the remaining 8 patients, none showed a phenotype invoking the Silver-Russell syndrome in contrast to our patient. The clinical comparison between these patients and the diagnostic criteria for SRS are reported in table 1.

In detail, Sanchez et al. [1974] described a partial trisomy 11 in a child with severe psychomotor retardation, intermittent exotropia, oval shaped pupils, leg spasticity, intestinal malrotation, and some craniofacial dysmorphisms; later, Palutke et al. [1980] reported a female pa- 
Table 2. Candidate genes for the observed phenotypes in our patient

\begin{tabular}{ll}
\hline Gene symbol & Description \\
\hline ELP4 & $\begin{array}{l}\text { elongator acetyltransferase complex subunit 4 } \\
\text { cell cycle-associated protein 1 }\end{array}$ \\
CAPRIN1 & $\begin{array}{l}\text { solute carrier family 1 (glial high-affinity } \\
\text { glutamate transporter), member 2 }\end{array}$ \\
FJX1 & four jointed box 1 (Drosophila) \\
MIR1343 & microRNA 1343 \\
LINC00294 & long intergenic non-protein coding RNA 294 \\
\hline
\end{tabular}

tient with a dup11p12p14 showing disconjugate eye movements, ventricular septal defects and dysmorphic features, while Strobel et al. [1980] described an infant with macular dysfunction, cleft lip and palate and developmental delay who was a carrier of a large duplication involving the $11 \mathrm{p} 11.3$ band.

Few years later, a mentally retarded child with a $\operatorname{dup}(11)(p 13)$ [Lavedan et al., 1989] and a child with mild mental retardation, but no other remarkable dysmorphic characteristics [Speleman et al., 1991] were described. Subsequently, Aalfs et al. [1997] reported the data of a girl with a duplication of chromosome band 11p12p13 with borderline developmental delay, mild facial anomalies and eye abnormalities. More recently, a girl, carrier of a small 11p13 duplication comprising 135-168 kb and encompassing only the PAX6 gene, with seizures, developmental delay, microcephaly, and ocular findings has been described by Aradhya et al. [2011], and a duplication of $5.5-5.8 \mathrm{Mb}$ in size has been reported in a healthy patient by Dolan et al. [2011].

The variable phenotypes in patients described with 11 p13 duplications may be related to the different sizes of the rearrangements, to polymorphisms, mutations or different genetic factors elsewhere in the genome, environmental factors, incomplete penetrance, or variable expressivity. Obviously, further molecular analyses are essential to clarify this point.

The potential clinical relevance of the duplication present in our patient is supported by its gene content. The $4.3-\mathrm{Mb}$ duplicated region contains 42 genes (30 known protein-coding genes, 8 pseudogenes, 2 open reading frames, 1 miRNA gene, and 1 long noncoding RNA gene); we suggest and discuss some of them as functional candidates contributing to the phenotype observed in the patient (table 2). In particular, we suggest as candidates for the psychomotor retardation CAPRIN1, SLC1A2 and FJX1.
CAPRIN1 encodes a protein that induces the formation of RNA granules, which regulate the transport and translation of mRNAs of proteins involved with synaptic plasticity in neurons. Loss of these control mechanisms is implicated in neuronal disorders. In particular, Shiina et al. [2010] demonstrated that CAPRIN1 deficiency impairs the dendritic localization of mRNAs for $\mathrm{Na}^{+} / \mathrm{K}^{+}$ ATPase subunit isoforms leading to the degeneration of neuronal networks. Also, the protein CAPRIN1 interacts with the fragile $\mathrm{X}$ mental retardation protein, involved in Fragile-X syndrome phenotype, in neuronal ribonucleoprotein complexes modulating its function [El Fatimy et al., 2012].

The gene SLC1A2 encodes a member of a family of solute transporter proteins that transports L-glutamate and L- and D-aspartate. In particular, it is essential for terminating the postsynaptic action of glutamate by removing it from the extracellular space at synapses in the central nervous system. Some authors proposed the downregulation of this gene as an adaptive response to neuronal death or a causative event contributing to neuronal death, suggesting it as a possible susceptibility gene to idiopathic epilepsy [Sarac et al., 2009]. Also, in the 11p13 microdeletion patients, Xu et al. [2008] proposed SLC1A2 and $B D N F$ as candidates that may contribute to autism and mental retardation.

Although the experimental evidences show that haploinsufficiency of these genes, CAPRIN1 and SLC1A2, can give a neurological phenotype, we cannot exclude that also the duplication of the same has a negative effect on the phenotype as already demonstrated for several other genes [Franco et al., 2010; Mattina et al., 2012].

In addition, as regards the psychomotor retardation, we propose the gene FJX1 as a good candidate. The protein encoded by this gene is the human ortholog of Drosophila and mouse four jointed gene product. The Drosophila gene four jointed is important for growth and differentiation of legs and wings and for proper development of the eyes while the mouse four jointed gene is expressed in the brain during embryogenesis and in the adult. Although the exact function of the protein encoded by this gene in humans is not known, animal models identify the four jointed gene as an inhibitor of dendrite extension and branching [Probst et al., 2007].

A possible candidate for the prenatal and postnatal growth retardation may be the ELP4 gene, the product of which is a histone acetyltransferase component of the RNA polymerase II holoenzyme. It is involved in transcriptional elongation. Elongators may play a role in chromatin remodeling and are involved in acetylation of
16

Mol Syndromol 2014;5:11-18 DOI: $10.1159 / 000356459$
Palumbo/Mattina/Palumbo/Carella/ Perrotta 
histone $\mathrm{H} 3$ and probably $\mathrm{H} 4$. Chromatin dynamism is critical to basic cellular processes and is modulated by epigenetic mechanisms that alter the structure of the chromatin providing binding sites for a wide variety of regulatory proteins. Over the last decade, it has become increasingly clear that genetic alterations of genes involved in epigenetic mechanism are linked to human disorders and in particular to genetic conditions presenting pre- and/or postnatal growth alterations [Hennekam, 2006, Franco et al., 2010]. Also, some authors described carrier patients showing clear growth retardation and deletions or duplications of genes involved in chromatin remodeling, like CHD1L [Spengler et al., 2012] and CREBBP [Mattina et al., 2012], supporting the hypothesis that alterations of this pathway may result in growth defects. Although, to date, there are no reported cases in the literature documenting that the overexpression and/or microduplication of ELP4 may have phenotypic consequences, given its functional role, we believe that ELP4 is a good candidate for the features of growth retardation reported in our case. Of course, to confirm or reject our hypothesis, it is necessary that other patients, perhaps with a small duplication of only ELP4, are described.

Interestingly, 2 noncoding RNAs, MIR1343 and LINC00294, are located within the duplicated region. Several reports indicated a role of noncoding RNAs in the molecular pathogenesis of different developmental disorders as well as that alterations of miRNA pathways could be implicated in the etiology of several genomic disorders [Xu et al., 2010]. We searched in the miRBase database (http://mirdb.org/miRDB/) for mRNAs containing a putative MIR1343 binding site. This analysis revealed a large number of putative MIR1343 target mRNAs (data not shown). Among these mRNAs, the most interesting one, with one of the highest scores, was IGFBP5 that could be related with the growth retardation observed in our patient.

IGFBP 5 codes for a protein, belonging to the insulinlike growth factor-binding protein family that contributes to modulate insulin-like growth factor actions. Mouse models have shown that alteration of the expression levels of IGFBP5 is associated with growth retardation [Salih et al., 2004]. Although we have no experimental evidences, we suppose that alterations of its expression pattern could be causative of or jointly responsible for growth delay in our patient. As miRNAs function as negative regulators of gene expression, we hypothesize that the duplication of one of these noncoding RNAs could cause an altered expression of the target genes. This hypothesis is compatible with what is already documented

11 p13 Microduplication in a SRS-Like Patient in some microdeletion syndromes, for example in 22q11.2 [Xu et al., 2013], or is proposed for other microduplication syndromes, such as for 8p23.1 [Barber et al., 2013]. Thus, we suggest that IGFBP5 could be characterized by a similar mechanism, and therefore, growth retardation in our patient may be caused by MIR1343 duplication.

The last gene that we proposed to play a role in the etiology of the clinical features shown by our patient is LINC00294 which encodes a long noncoding RNA. The majority of the long noncoding RNAs have very high levels of expression in the central nervous system in a cell type-specific manner, of which some have already been implicated in neurological and developmental disorders [Qureshi et al., 2010]. It is assumed that they regulate gene expression notably via chromatin remodeling at their original locus (in cis) and/or elsewhere in the genome (in trans). This property considerably increases the difficulty to identify their triggers and to understand their physiological roles. Nevertheless, since they are mainly expressed and perform their functions in the central nervous system and given that they regulate gene expression through mechanisms of chromatin remodeling, LINC00294 still remains a good candidate to explain psychomotor retardation and growth delay observed in our proband. Obviously, to confirm this suggestive hypothesis, gene expression or functional analyses are needed. In conclusion, this is the first paper describing a SRS-like patient being a carrier of a $11 \mathrm{p} 13$ microduplication detected by SNP array analysis. We suggest that CAPRIN1, SLC1A2, FJX1, and ELP4 are good candidate genes responsible for the observed traits, and we propose, for the first time, the possible involvement of MIR1343 and LINC00294 in the determination of the phenotype. Detailed clinical and molecular examinations of additional patients with a similar microduplication are needed to establish a more accurate genotype-phenotype correlation. Finally, this study demonstrates the utility of molecular karyotyping to discover submicroscopic imbalances in idiopathic SRS or SRS-like patients.

\section{Acknowledgements}

This study was supported by a grant of the Italian Ministry of Health (Ricerca Corrente 2013) and by the ' $5 \times 1000$ ' voluntary contributions. We are grateful to the patient and his parents for their cooperation, and we are very thankful to Dr. Andrea Riccio, $\mathrm{MD}$, for reviewing the paper. 


\section{References}

-Aalfs CM, Fantes JA, Wenniger-Prick LJJM, Sluijter S, Hennekam RC, et al: Tandem duplication of 11 p12-p13 in a child with borderline development delay and eye abnormalities: dose effect of the PAX6 gene product? Am J Med Genet 73:267-271 (1997).

-Abu-Amero S, Monk D, Frost J, Preece M, Stanier P, Moore GE: The genetic aetiology of Silver-Russell syndrome. J Med Genet. 45:193199 (2008).

-Aradhya S, Smaoui N, Marble M, Lacassie Y: De novo duplication $11 \mathrm{p} 13$ involving the PAX6 gene in a patient with neonatal seizures, hypotonia, microcephaly, developmental disability and minor ocular manifestations. Am J Med Genet A 155A:442-444 (2011).

-Barber JC, Rosenfeld JA, Foulds N, Laird S, Bateman MS, Thomas NS, et al: 8p23.1 duplication syndrome; common, confirmed, and novel features in six further patients. Am J Med Genet 161:487-500 (2013).

Bruce S, Hannula-Jouppi K, Puoskari M, Fransson I, Simola KO, et al: Submicroscopic genomic alterations in Silver-Russell syndrome and Silver-Russell-like patients. J Med Genet 47:816-822 (2010).

Coutton C, Devillard F, Vieville G, Amblard F, Lopez G, et al: 17p13.1 microduplication in a boy with Silver-Russell syndrome features and intellectual disability. Am J Med Genet A 158A:2564-2570 (2012).

Dolan M, Berry SA, Rubin KR, Hirsch B: Deletion and duplication of 11p13-11p14: reciprocal aberrations derived from a paternal insertion. Am J Med Genet A 155A:2775-2783 (2011).

-Eggermann T, Begemann M, Binder G, Spengler S: Silver-Russell syndrome: genetic basis and molecular genetic testing. Orphanet J Rare Dis 5:19 (2010).

El Fatimy R, Tremblay S, Dury AY, Solomon S, De Koninck P, et al: Fragile X mental retardation protein interacts with the RNA-binding protein Caprin 1 in neuronal RiboNucleoProtein complexes. PLoS One 7:e39338 (2012).
Fischbach BV, Trout KL, Lewis J, Luis CA, Sika M: WAGR syndrome: a clinical review of 54 cases. Pediatrics 116:984-988 (2005).

Franco LM, de Ravel T, Graham BH, Frenkel SM, Van Driessche J, et al: A syndrome of short stature, microcephaly and speech delay is associated with duplications reciprocal to the common Sotos syndrome deletion. Eur J Hum Genet 18:258-261 (2010).

-Hennekam RCM.: Rubinstein-Taybi syndrome. Eur J Hum Genet 14:981-985 (2006).

Lavedan C, Barichard F, Azoulay M, Couillin P, Molina Gomez D, et al: Molecular definition of de novo and genetically transmitted WAGR-associated rearrangements of $11 \mathrm{p} 13$. Cytogenet Cell Genet 50:70-74 (1989).

Mattina T, Palumbo O, Stallone R, Pulvirenti RM, Di Dio L, et al: Interstitial 16p13.3 microduplication: case report and critical review of genotype-phenotype correlation. Eur J Med Genet 55:747-752 (2012).

Palumbo O, Palumbo P, Palladino T, Stallone R, Miroballo M, et al: An emerging phenotype of interstitial 15q25.2 microdeletions: clinical report and review. Am J Med Genet A 158A:3182-3189 (2012).

Palutke W, Tyrkus M, Gohle N, Bawle E, Woolley $\mathrm{PV}$ : Intra-segmental duplication resulting in partial trisomy 11p: case report and cytogenetic documentation. Am J Hum Genet 32: 83A (1980).

Probst B, Rock R, Gessler M, Vortkamp A, Püschel AW: The rodent Four-jointed ortho$\log$ Fjx1 regulates dendrite extension. Dev Biol 312:461-470 (2007).

Qureshi IA, Mattick JS, Mehler MF: Long noncoding RNAs in nervous system function and disease. Brain Res 1338:20-35 (2010).

Salih DA, Tripathi G, Holding C, Szestak TA, Gonzalez MI, et al: Insulin-like growth factorbinding protein 5 (Igfbp5) compromises survival, growth, muscle development, and fertility in mice. Proc Natl Acad Sci USA 101: 4314-4319 (2004).
Sanchez O, Yunis JJ, Escobar JI: Partial trisomy 11 in a child resulting from a complex maternal rearrangement of chromosomes 11, 12 and 13. Humangenetik 22:59-65 (1974).

Sarac S, Afzal S, Broholm H, Madsen FF, Ploug T, Laursen $\mathrm{H}$ : Excitatory amino acid transporters EAAT-1 and EAAT-2 in temporal lobe and hippocampus in intractable temporal lobe epilepsy. APMIS 117:291-301 (2009).

Shiina N, Yamaguchi K, Tokunaga M: RNG105 deficiency impairs the dendritic localization of mRNAs for $\mathrm{Na}+/ \mathrm{K}+$ ATPase subunit isoforms and leads to the degeneration of neuronal networks. J Neurosci 30:12816-12830 (2010).

-Speleman F, Mannens M, Redeker B, Vercruyssen $\mathrm{M}$, Van Oostveldt $\mathrm{P}$, et al: Characterization of a de novo duplication of $11 \mathrm{p} 14-\mathrm{p} 13$, using fluorescent in situ hybridization and Southern hybridization. Cytogenet Cell Genet 56: 129-131 (1991).

Spengler S, Begemann M, Ortiz Brüchle N, Baudis M, Denecke B, et al: Molecular karyotyping as a relevant diagnostic tool in children with growth retardation with Silver-Russell features. J Pediatr 161:933-942 (2012).

Strobel RJ, Riccardi VM, Ledbetter DH, Hittner HM: Duplication 11p11.3 leads to 14.1 to meiotic crossing-over. Am J Med Genet 7:1520 (1980).

Xu B, Karayiorgou M, Gogos JA: MicroRNAs in psychiatric and neurodevelopmental disorders. Brain Res 1338:78-88 (2010).

Xu B, Hsu PK, Stark KL, Karayiorgou M, Gogos JA: Derepression of a neuronal inhibitor due to miRNA dysregulation in a schizophreniarelated microdeletion. Cell 152:262-275 (2013).

Xu S, Han JC, Morales A, Menzie CM, Williams K, Fan YS: Characterization of 11p14-p12 deletion in WAGR syndrome by array CGH for identifying genes contributing to mental retardation and autism. Cytogenet Genome Res 122:181-187 (2008). 